\title{
Neurobehavioural effects and pharmacokinetics of toluene in rats and their relevance to man
}

\author{
R KISHI, I HARABUCHI, T IKEDA, H YOKOTA, H MIYAKE \\ From the Department of Public Health, Sapporo Medical College, Sapporo, Japan
}

\begin{abstract}
The present study was designed to determine the critical concentrations in blood and brain associated with specific behavioural changes during and after exposure to toluene. The effects of a single four hour exposure to toluene on signalled bar press shock avoidance in rats were tested. Rats exposed to 125,250 , and $500 \mathrm{ppm}$ toluene showed a decline in conditioned avoidance responses at 20 minutes exposure compared with the pre-exposure baseline, although they recovered to almost the same level of performance as that before exposure. Exposure to $1000 \mathrm{ppm}$ toluene for about four hours and $2000 \mathrm{ppm}$ for two hours produced a concentration related increase in incorrect responses, acceleration of the reaction time, and decreases in the effective avoidance response rate. Beginning at $4000 \mathrm{ppm}$ toluene exposure, the response rate increased; thereafter, it gradually decreased and finally slight ataxia was observed. After $4000 \mathrm{ppm}$ exposure, all rats showed signs of excitation such as a pronounced increase in response rate. From analysis of the temporal courses of the blood and brain toluene concentrations during and after each exposure, excitative performance decrements were noticed in rats with blood and brain concentrations about $27 \mu \mathrm{g} / \mathrm{ml}$ blood and $32 \mu \mathrm{g} / \mathrm{g}$ respectively. Anaesthetic performance decrements were seen when the blood toluene concentration increased to $120 \mu \mathrm{g} / \mathrm{ml}$ and that of the brain reached about $160 \mu \mathrm{g} / \mathrm{g}$. According to our results, the effects on the central nervous system are considered to be a function of both the exposure concentration and its duration, which are closely related to the increase of brain and blood toluene concentration.
\end{abstract}

Toluene is used extensively in industry as a solvent, an additive in motor and aviation fuels, and an intermediate in the manufacture of chemicals. With the recognition of the hazards of benzene and its replacement with methylated derivatives, the use of toluene is becoming even more widespread.

Toluene is a highly lipid soluble and readily disperses in the central nervous system. Symptoms of the central nervous system such as headache, dizziness, euphoria, abnormal electroencephalograms, and deficits in psychomotor performance have been reported in workers exposed to toluene vapour or toluene based lacquers or thinners.'

Nervous system dysfunction induced by short term exposure to toluene has been studied in both $\operatorname{man}^{2-4}$ and animals. ${ }^{5-7}$ Most animal studies have used the method of operant conditioning using various reinforcement schedules. ${ }^{8}$ From the available information it is difficult to determine such basic issues as $(a)$

Accepted 11 May 1987 what are the extent and threshold of the effects and $(b)$ what is the nature or mechanism of the effect. This confusion is especially due to a lack of precise data on toluene concentrations in the target organs (brain and blood) and the lack of a statistically adequate experimental design: many of the early studies are based on too few animals, for example.

With experimental exposures to organic solvents it is especially important to measure target organ tissue levels in order to assess possible threshold or saturation effects or other dose related non-linearities. In addition, little evidence is available on the whole time course of toluene intoxication during and after exposure. From this viewpoint, we studied the neurobehavioural effects of single exposures to toluene in rats using conditioned avoidance performance and estimated the blood and brain toluene concentrations during and after such exposure.

\section{Methods}

ANIMALS AND APPARATUS

Male Wistar rats 7 weeks old were used in the 
experiment. All experiments were performed under a dark light cycle consisting of alternating 12 hour periods, the dark period beginning at 0700 . The setup used in the behavioural test consisted of Skinner boxes that were placed in a gas chamber with programming and recording equipment. A shock generator and scrambler (BRS/LVE) were used to deliver a $2.5 \mathrm{~mA}$ DC shock to the grid floor of each Skinner box for $0.2 \mathrm{~s}$. The experimental contingencies were controlled by a Sord M23 microcomputer and related peripherals.

\section{EXPOSURE}

Static exposure was carried out in two similar stainless steel gas chambers $(70 \times 70 \times 120 \mathrm{~cm}) .{ }^{9}$ The two chambers were simultaneously exposed, a calculated volume of toluene being introduced from an upper inlet by using a vaporiser. Rats were exposed to various concentrations of toluene $(125,250,500,1000$, 2000 , and $4000 \mathrm{ppm}$, in ascending order) and to air under identical conditions in each exposure. Toluene vapour concentration was determined with a Shimazu 4 BPTF gas chromatograph.

\section{BEHAVIOURAL PROCEDURE}

The shock avoidance response ${ }^{10}$ (fixed negative interval schedule with a light signal) was used to establish a behavioural baseline for the observation of behavioural changes after exposure to toluene. The animals were trained for one hour every two days with a reinforcement schedule of having a 10 second shockto-shock interval, a light signal being presented for five seconds before every electric shock. Under this schedule, the animals could avoid an electric shock if they pressed a lever when the light signal was on.

The behavioural baseline was established in the animals after 10 to 15 training sessions. After this, eight rats whose avoidance rate was successful in over $80 \%$ of the trials were selected and alternately exposed first to air, as a control, and then to toluene. The animals were placed in Skinner boxes to test their lever pressing behaviour under the above avoidance schedule beginning at 0900 every day. They were exposed to toluene or air for four hours from 1000 to 1400 and observations were continued for about two hours after the exhaustion of toluene. The interval between exposures to toluene for any single rat was set at 10-20 days to avoid the lingering effects of the previous exposure. The numbers of lever presses and shocks received per 20 minute period during these seven hour test periods and the latency to the light signal were adopted as the behavioural test parameters.

SOLVENT ANALYSIS

To measure the blood and brain toluene concentration during and after the exposure, a total of 220 male
Wistar rats equivalent in weight to the animals of the behavioural experiment were used. They were exposed to toluene for four hours at the same concentrations as those in the behavioural experiments $(125,250,500$, 1000,2000 , and $4000 \mathrm{ppm}$ ). The rats were then killed and blood was dispensed into an all glass container with heparin. The brain was then removed. The concentration of toluene in blood and brain was determined by the modified gas chromatographic equilibration method of Sato et al."

\section{STATISTICAL ANALYSIS}

The effects of toluene were evaluated by comparing the performance of rats during and after their own performance under an air dummy exposure. The statistical significance of the experimental results was determined by a three way analysis of variance, in which the exposure effects, time effects, and the differences within the eight individual rats were included as the three factors.

\section{Results}

Exposure to $125 \mathrm{ppm}$ toluene induced a considerable decrease in the effective avoidance response rate during the initial 20 minutes of exposure compared with the matched air control. The effective avoidance response rate was slightly, but appreciably, lower than that of controls in periods $E$ and $F$ - that is, before and after 240 minutes of exposure (fig 1 ). The $250 \mathrm{ppm}$ and $500 \mathrm{ppm}$ toluene exposures also induced appreciable increases in the total number of lever presses and considerably decreased the effective avoidance response rate in the initial 20 minutes after exposure, although they later recovered to almost the same level of performance as before the exposure. In period $\mathrm{H}$ (figs 2,3 ) the lever press behaviour after the $250 \mathrm{ppm}$ and $500 \mathrm{ppm}$ toluene exposures was a little lower than that under control conditions.

Exposure to $1000 \mathrm{ppm}$ toluene produced an exposure duration related to the increase in the total number of lever presses and decreases in the effective response rate. Rats exposed to $1000 \mathrm{ppm}$ toluene for at least 80 minutes showed a statistically significant increase in the total number of lever presses, which implies a decrease in the effective avoidance response rate and incorrect responses (fig 4).

The total number of lever presses increased drastically after exposure to $2000 \mathrm{ppm}$ toluene. Rats exposed to $2000 \mathrm{ppm}$ toluene for four hours showed the most extreme excitation. Under these circumstances, total lever presses, expressed as the per cent of each pretest performance, exceeded $150 \%$. The effective avoidance response rate decreased to about $70 \%$ compared with the pretest performance (fig 5).

A statistically significant acceleration of the reac- 
Fig 1 Performance changes of rats during and after a four hour 125 ppm inhalation exposure to toluene. 


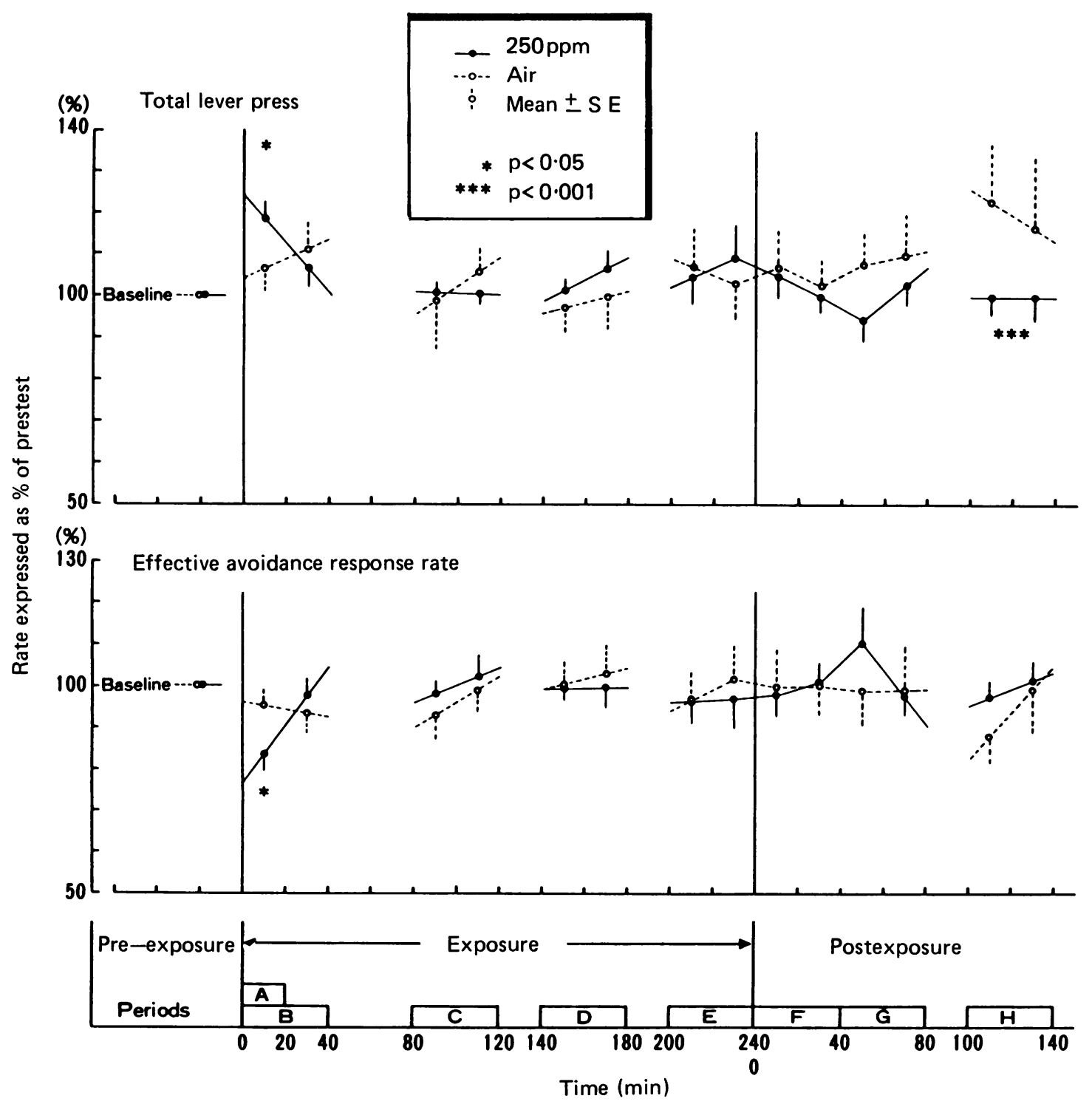

Fig 2 Performance changes of rats during and after a four hour 250 ppm inhalation exposure to toluene. 


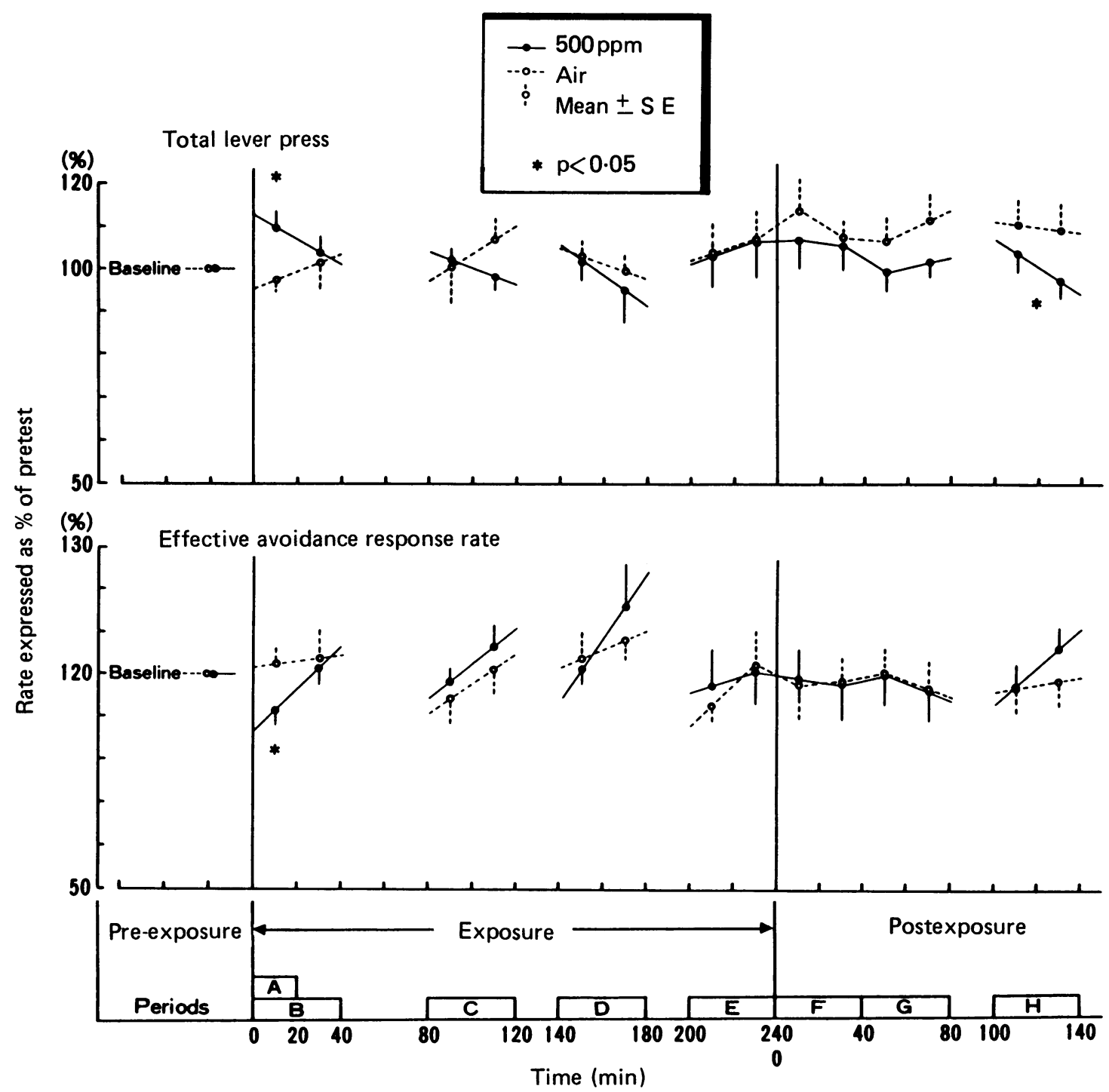

Fig 3 Performance changes of rats during and after a four hour 500 ppm inhalation exposure to toluene. 




Fig 4 Performance changes of rats during and after a four hour 1000 ppm inhalation exposure to toluene. 


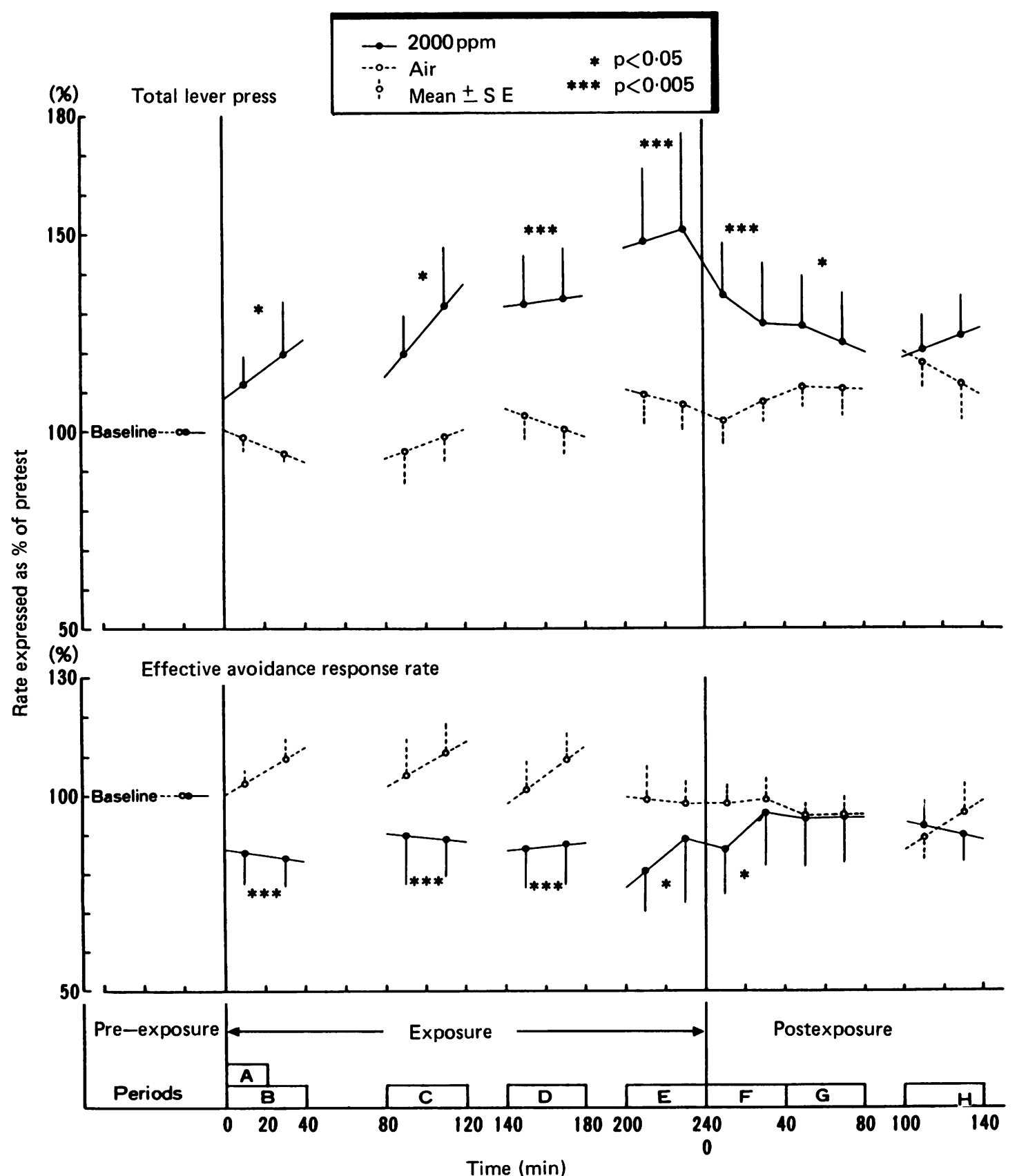

Fig 5 Performance changes of rats during and after a four hour 2000 ppm inhalation exposure to toluene. 




Fig 6 Performance changes of rats during and after a four hour 4000 ppm inhalation exposure to toluene. 


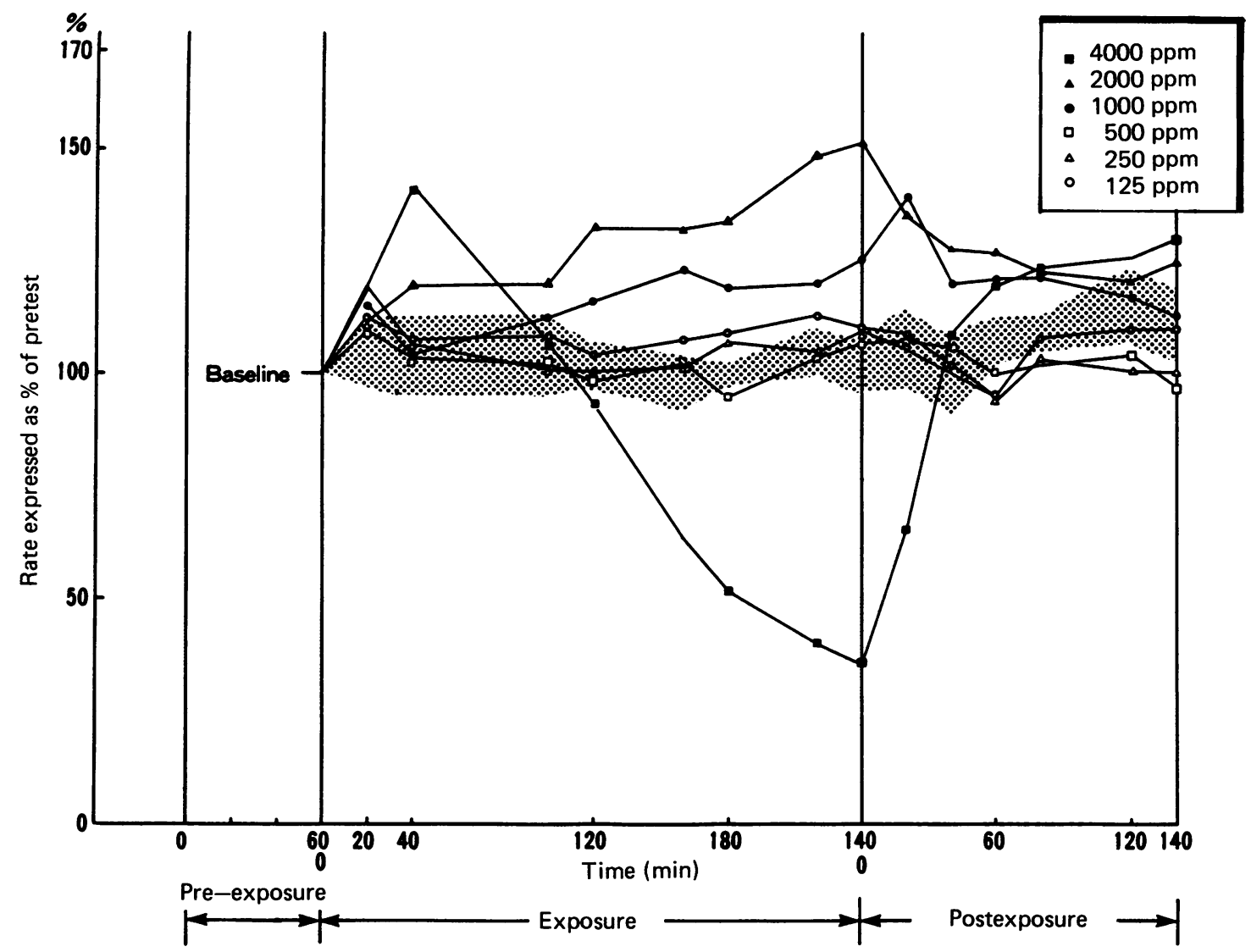

Fig 7 Dose response relation of toluene exposure to number of lever presses. Each point indicates mean total of lever presses expressed as percentages of pretest of eight rats during seven hour test periods under each toluene concentration. Dotted shadows show range of control exposure of an air dummy, which includes minimum and maximum points.

tion time was observed after exposure to 1000 and $2000 \mathrm{ppm}$ toluene. The mean latencies of eight rats exposed to 1000 and $2000 \mathrm{ppm}$ toluene were $2 \cdot 2 \mathrm{~s}$ and $2 \cdot 1 \mathrm{~s}$, respectively, whereas respective mean latencies with dummy exposure were $2.6 \mathrm{~s}$ and $2.5 \mathrm{~s}$. Three or four of these animals showed the shortest latency, less than $2.0 \mathrm{~s}$ under exposure to 1000 or $2000 \mathrm{ppm}$ toluene.

Beginning at $4000 \mathrm{ppm}$ exposure (especially during the initial 40 minutes), the response rate increased remarkably; thereafter, it gradually decreased. Finally, slight ataxia was observed in six of the eight rats. . After exposure to $4000 \mathrm{ppm}$ ceased all the animals showed signs of excitation such as a pronounced increase in the response rate (fig 6).

Figures 7 and 8 summarise the dose response relation of total lever presses (fig 7) and the effective avoidance response rate (fig 8 ) under the different toluene concentrations. Clearly toluene produces a performance deficit that is related to concentration and time during and after exposure to toluene. The performance disorder in animals continued until 140 minutes after exposure to toluene vapour ceased. Nevertheless, exposure to 1000 and $2000 \mathrm{ppm}$ toluene produced concentration and time duration related increases in lever presses: the $\mathbf{4 0 0 0} \mathrm{ppm}$ four hour exposure to toluene had different features.

Figure 9 shows toluene uptake (inhalation) and elimination in whole brain or blood of rats exposed to from 125 to $4000 \mathrm{ppm}$ toluene for four hours. The concentration of toluene in the blood and brain depended on the concentration of toluene inhaled by 




Fig 8

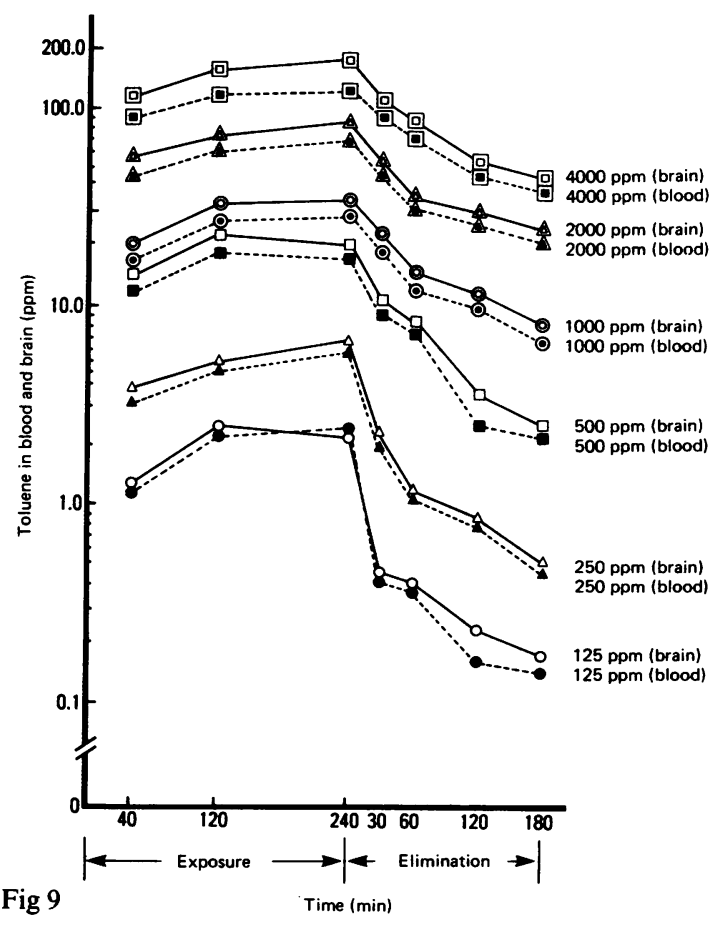

Fig 8 Dose response relation of toluene exposure to effective avoidance response rate. Each point indicates mean effective avoidance response rate expressed as a percentage of pretest of eight rats during seven hour test periods under each toluene concentration. Dotted shadow shows range of control exposure of an air dummy, which includes minimum and maximum points.

Fig 9 Concentrations of toluene in blood and brain of rats during and after four hour inhalation exposure to toluene. Each point represents geometrical mean of five to six rats. 

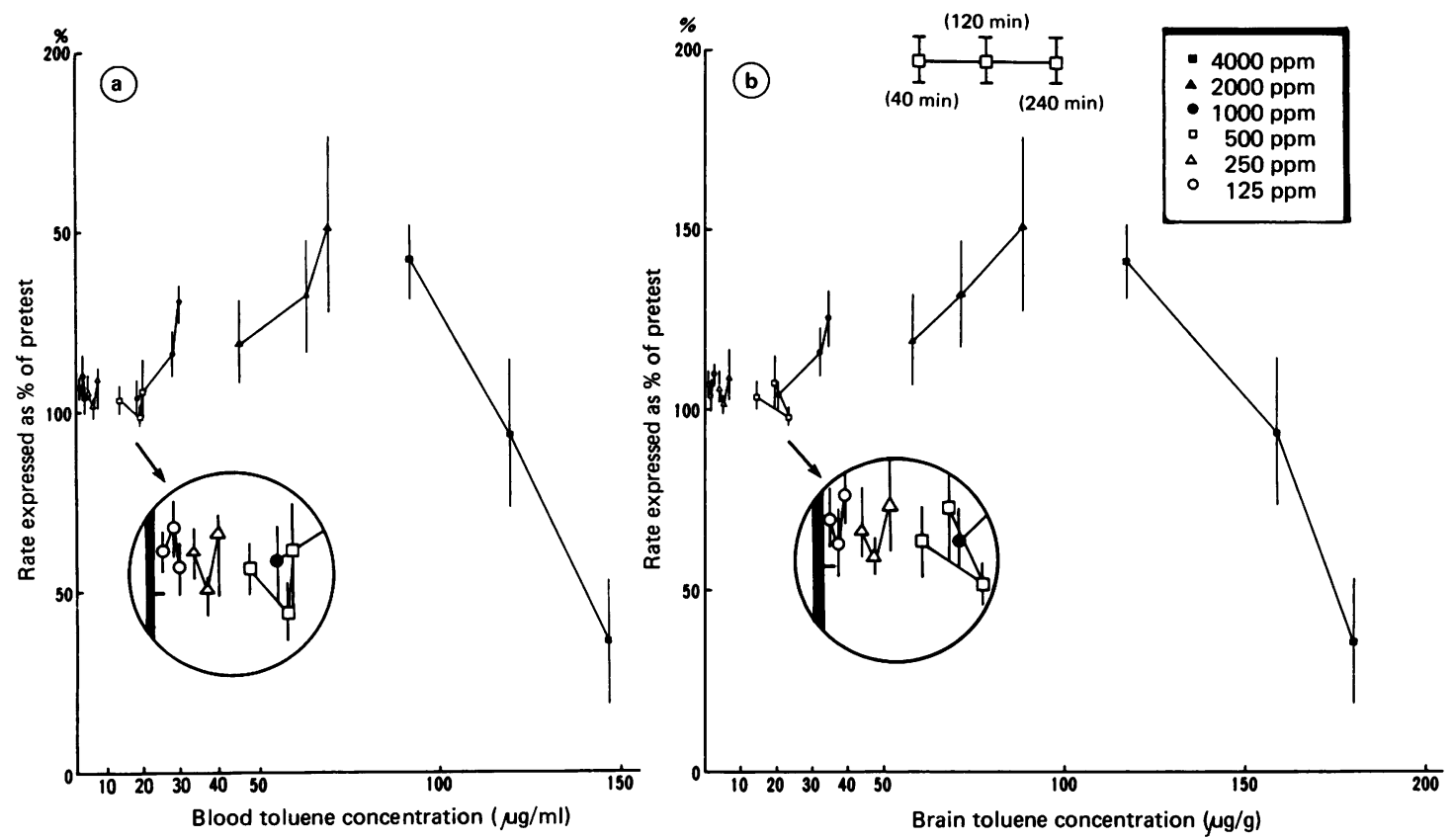

Fig 10 Relation between number of lever presses and blood (a) or brain (b) level. Mean and standard error of lever pressing in eight rats at exposures for 20-40 minutes, 100-120 minutes, and 220-240 minutes are plotted against mean toluene concentrations in blood or brain measured at corresponding time.

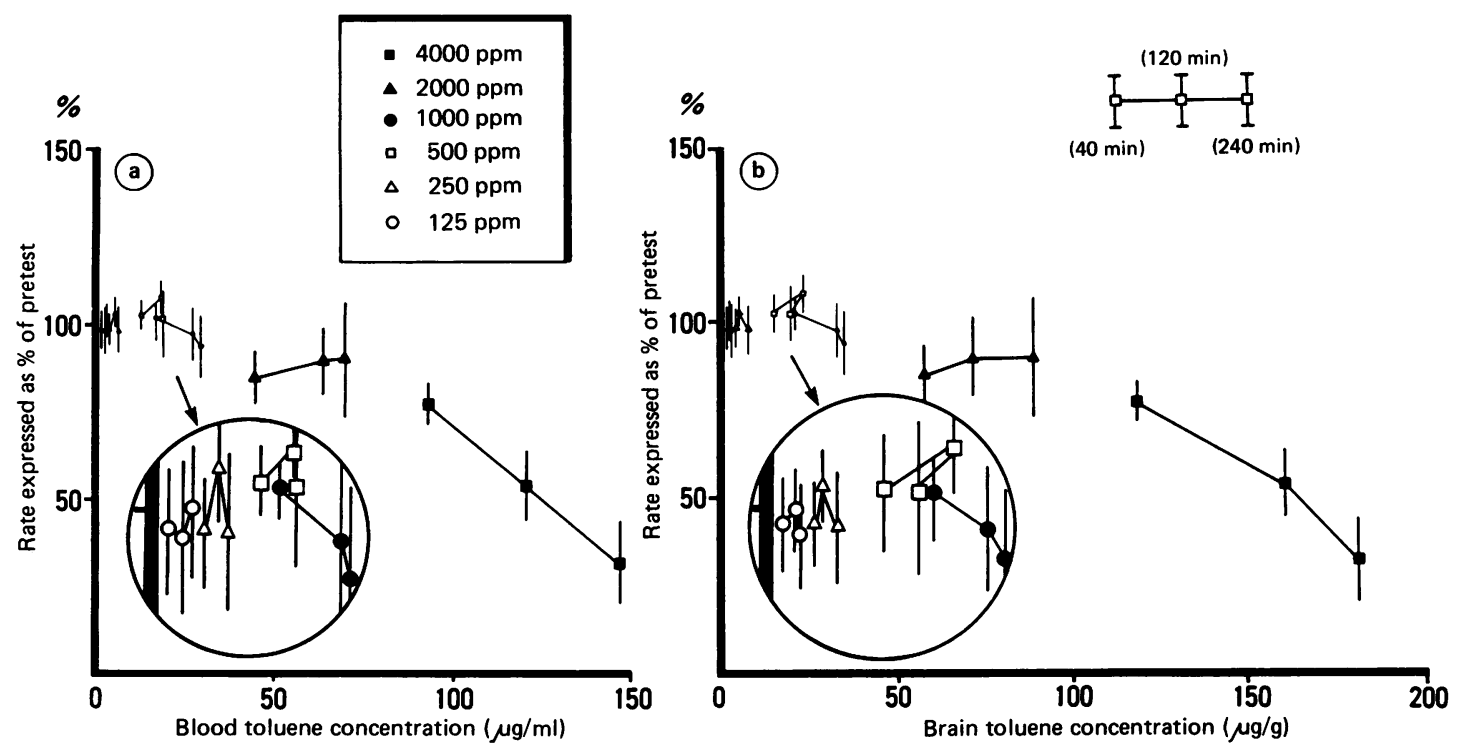

Fig 11 Relation between effective avoidance rate and blood (a) or brain (b) toluene concentration. Mean and standard error of lever pressing in eight rats at exposures for 20-40 minutes, 100-120 minutes, and 220-240 minutes are plotted against mean toluene concentrations in blood or brain measured at corresponding times. 
the animals. The brain/blood ratio was about 1.20. Fluctuations in blood concentrations were similar to those in the brain during exposure to the solvent and recovery. On the whole, there was a progressive increase in the quantity of toluene in both blood and brain throughout the four hour inhalation period; most of the increase occurred during the initial hour of exposure.

Figures 10 and 11 show the relation between the number of lever presses or the effective avoidance rate and the brain and blood toluene concentrations, estimated from the results of each exposure. From analysis of the temporal courses of blood and brain toluene concentrations during each exposure, clear dose related performance decrements, with decreases in the effective response rate and acceleration of the reaction time, were noticed in rats with blood and brain concentrations of about $26.8 \mu \mathrm{g} / \mathrm{ml}$ (which is the mean concentration at $1000 \mathrm{ppm}, 120$ minutes exposure) $-69.6 \mu \mathrm{g} / \mathrm{ml}$ blood (2000 ppm, 240 minutes exposure) and $32.2 \mu \mathrm{g} / \mathrm{g}-88.5 \mu \mathrm{g} / \mathrm{g}$ for brain respectively. There were typical signs of anaesthetic central nervous system depression in rats and the corresponding concentrations were $120 \mu \mathrm{g} / \mathrm{ml}$ blood $(4000 \mathrm{ppm}$, 120 minute exposure) and $159 \mu \mathrm{g} / \mathrm{g}$ brain. The increase in the total number of lever presses was almost linear with the increase in the blood and brain toluene concentrations. This behavioural effect seems to be rather directly dependent on the brain toluene concentration, which is affected by the exposure concentration and by the time period after exposure.

\section{Discussion}

Our study suggests that even low levels of exposure to toluene induce shock avoidance performance decrements in rats. Performance decrements were observed immediately after the beginning of 125,250 , and $500 \mathrm{ppm}$ toluene exposures (period A). This coincides well with the result that irritation in the eyes, nose, and throat is highest in the first hour in the average subjective rating of people exposed to 100 ppm toluene.

A decrease in the total number of lever presses was detected at two hours after the cessation of 125, 250, and $500 \mathrm{ppm}$ exposures (period $\mathrm{H}$ ), even though the dose response relation under exposure to $500 \mathrm{ppm}$ toluene was not so clear. The reason why performance decrements with $125 \mathrm{ppm}$ toluene exposure were greater than those with $250 \mathrm{ppm}$ or $500 \mathrm{ppm}$ exposure might be explained by the so called first exposure effect. We observed the same phenomenon, that the first exposure induced stronger effects than the second or third in our other experiments on rats and mice exposed to toluene. ${ }^{1213}$ Since no anaesthetic signs were observed with exposure to $500 \mathrm{ppm}$ toluene, both the decreases in the total number of lever presses and the effective avoidance response rate observed are considered to be related to the fatigue, headache, or sleepiness of healthy volunteers exposed to low concentrations of toluene at the workplace. ${ }^{14}$

As regards human performance at rest, Gamberale and Hultengren found impaired performance in tests of simple and choice reaction times at a concentration of $300 \mathrm{ppm}^{2}$ On the other hand, Dick et al reported that four hours of exposure to toluene at $100 \mathrm{ppm}$ produced a small but appreciable impairment in one measure of a visual vigilance task by lowering the percentage of correct hits. ${ }^{3}$ Our experimental study coincides well with the human exposure chamber studies with toluene by Baelum et al. ${ }^{4}$ Their investigation showed that the central nervous system is the organ most sensitive to exposure to toluene, and that $100 \mathrm{ppm}$ for 6.5 hours gave rise to a small but appreciable impairment in the performance of tasks relevant to normal work. The subjects thought that psychometric tests were more difficult and strenuous after exposure to $100 \mathrm{ppm}$ for six hours, and headache, dizziness, and feelings of intoxication were considerably more often reported, although exposures to 10 and $40 \mathrm{ppm}$ did not result in any adverse effects except for the perception of toluene odour.

Our results indicate that toluene is at some concentrations, such as 1000 or $2000 \mathrm{ppm}$, excitatory and at other concentrations, such as $4000 \mathrm{ppm}$, depressive. Both the acceleration of reaction time and increase in useless lever presses observed after exposures to 1000 and $2000 \mathrm{ppm}$ toluene showed over-reaction to exogenous stimuli, which induced incorrect responses to the light signal. The changes in the number of lever presses and the effective avoidance response rates in the present experiments correlate well with the changes in EEG components after exposure to toluene. Takeuchi and Hisanaga reported that in rats exposed to $1000 \mathrm{ppm}$ and $2000 \mathrm{ppm}$ group increases of the wakeful phase and decreases of the slow wave phase were observed, whereas the frequency of rhythmic hippocampal $\beta$ waves greatly increased in the 4000 ppm group. ${ }^{15}$

Special attention should be paid to the fact that the performance disorders continued for a fairly long period after exposure to toluene. Although the metabolism of toluene has been considered to be relatively rapid compared with other organic solvents, the results of these experiments showed that behavioural recovery from toluene was not so prompt. Even 80 minutes after exposure to $1000 \mathrm{ppm}$, excitatory behaviour such as an increase in the number of useless lever presses and shortening of response time to the light signal continued.

The main purpose of this study was to investigate the critical concentrations in blood and brain 
associated with specific behavioural changes during and after exposure to toluene. The biological effects of inhaled gases may be more closely related to blood or tissue concentration than to exposure air concentration. Unfortunately, only a few reports contain kinetic data on the measurement of concentrations of toluene during inhalation exposure. ${ }^{1617}$ In the present experiments the time required for equilibrium in blood and brain to be reached was about 60 minutes under $500 \mathrm{ppm}$ exposure, which corresponds well with that of Benignus et al..$^{16}$

According to our results, the effects on the central nervous system are considered to be functions of both the exposure concentration and its duration, and are closely related to the increases of brain and blood toluene concentrations. It is estimated that typical manifestations of central nervous system excitation and corresponding toluene concentrations were as follows: $27 \mu \mathrm{g} / \mathrm{ml}$ blood and $32 \mu \mathrm{g} / \mathrm{g}$ brain. Depression of the central nervous system with anaesthetic performance decrements was produced by blood toluene concentration of $120 \mu \mathrm{g} / \mathrm{ml}$ and brain toluene concentrations of over $160 \mu \mathrm{g} / \mathrm{g}$.

In the case of a sniffer suspected of being intoxicated by inhaling toluene and being drowned, blood analysis indicated a concentration of $50 \mu \mathrm{g} / \mathrm{ml}$ toluene, which was calculated to be equivalent to $2050 \mathrm{ppm}$ toluene in the environmental air. ${ }^{18}$ In the blood of those who had died because of toluene addiction Kashima et al reported blood toluene concentrations of 60 and 79 $\mu \mathrm{g} / \mathrm{ml} .{ }^{19}$ It is assumed that these blood concentrations decreased during the interval between death and specimen recovery and that the actual blood toluene concentrations were higher when it was being inhaled.

It seems that there are not such large differences of toluene concentration in blood between rats and man. The respective toluene concentrations in the blood of rats exposed to $125 \mathrm{ppm}$ and $250 \mathrm{ppm}$ of toluene were $2.5 \mu \mathrm{g} / \mathrm{ml}$ and $7.0 \mu \mathrm{g} / \mathrm{ml}$ in our experiment, whereas the toluene concentration in arterial blood of subjects exposed to 100 to $200 \mathrm{ppm}$ toluene was shown as about $2.0 \mu \mathrm{g} / \mathrm{ml}$ to $5 \cdot 0-6 \cdot 0 \mu \mathrm{g} / \mathrm{ml}{ }^{2021}$ Direct comparison between findings in man and those in animals must always be made with caution, but our results indicate that inhalation exposure to toluene impairs behavioural performance at concentrations considerably below those causing overt neurological signs, such as ataxia or other anaesthetic signs.

From our experiment, blood samples may be considered to be a reasonable index of the behavioural effects of toluene in experimental subjects, although the brain has a somewhat higher toluene tissue-blood partition coefficient than do liver and most other tissues except fat tissue. ${ }^{22}$

\section{References}

1 Sandmeyer IE. Aromatic hydrocarbons, toluene. In Clayton GD, Clayton FE, eds. Pattys industrial hygiene and toxicoloty. 3rd ed. Vol IIB. New York: Wiley, 1981:3283-91.

2 Gamberale F, Hultengren M. Toluene exposure. Psychophysiological function. Work Environ Health 1972;9:131-9.

3 Dick RB, Setzer JV, Wait R, et al. Effects of acute exposure to toluene and methyl ethyl ketone on psychomotor performance. Int Arch Occup Environ Health 1984;54:91-109.

4 Baelum J, Andersen LB, Lundqvist GR, et al. Response of solventexposed printers and unexposed controls to six-hour toluene exposure. Scand J Work Environ Health 1985;11:271-80.

5 Weiss B, Wood RW, Macys DA. Behavioral toxicology of carbon disulfide and toluene. Environ Health Perspect 1979;30:39-45.

6 Taylor JD, Evans HL. Effects of toluene inhalation on behavior and expired carbon dioxide in macaque monkeys. Toxicol Appl Pharmacol 1985;80:487-95.

7 Moser VC, Balster RL. Acute motor and lethal effects of inhaled toluene, 1,1,1-trichloroethane, halothane, and ethanol in mice: effects of exposure duration. Toxicol Appl Pharmacol 1985;77:285-91.

8 Benignus VA. Neurobehavioral effects of toluene: a review. Neurobehav Toxicol Teratol 1981;3:407-15.

9 Miyake H, Ikeda T, Maehara N, Harabuchi I, Kishi R, Yokota H. Slow learning in rats due to long-term inhalation of toluene. Neurobehav Toxicol Teratol 1983;5:541-8.

10 Ferster C, Skinner BF, Schedules of reinforcement. New York: Appleton-Century-Crofts, 1957.

11 Sato A, Nakajima T, Fujiwara H. Determination of benzene and toluene in blood by means of a syringe-equilibration method using a small amount of blood. Br J Ind Med 1975;32:210-4.

12 Harabuchi I, Kishi R, Ikeda T. A chronobiological study on avoidance performance in rats exposed to toluene. Sapporo Medical Journal 1984;53:359-71. (In Japanese with English abstract.)

13 Harabuchi I, Kishi R, Ikeda T, Kiyosawa H, Miyake H. A chronobiological study on toluene anesthesia in mice. Japanese Journal of Industrial Health 1984;26:279-82. (In Japanese with English abstract.)

14 von Oettingen WF, Neal PA, Donahue DD. The toxicity and potential dangers of toluene. $J A M A$ 1942;118:579-84.

15 Takeuchi $Y$, Hisanaga $H$. The neuro-toxicity of toluene: EEG changes in rats exposed to various concentrations. Br J Ind Med 1977;34:314-24.

16 Benignus VA, Muller KE, Barton CN, Bittikoffer JA. Toluene levels in blood and brain of rats during and after respiratory exposure. Toxicol Appl Pharmacol 1981;61:326-34.

17 Rees DC, Wood RC, McCormick JP, Cox C. Toxicokinetics of toluene in the rat. Scand J Work Environ Health 1985;11:301-6.

18 Nomiyama K, Nomiyama $H$. Three fatal cases of thinner-sniffing, and experimental exposure to toluene in human and animals, Int Arch Occup Environ Health 1978;41:55-64.

19 Kashima T, Fukui M, Masuda Y, Wakasugi C, Hayama R. Report of five cases where ordinary vinyl bag was used for suicidal purposes (suffocation, carbon monoxide poisoning and "thinner poisoning"). Japanese Journal of Forsenic Medicine 1969;23:248-52.

20 Åstrand I, Ehrner-Samuel H, Kilbom A, Ovrum P. Toluene exposure 1. Concentration in alveolar air and blood at rest and during exercise. Work Environ Health 1972;9:119-30.

21 Waldron HA, Cherry N, Johnson JD. The effects of ethanol on blood toluene concentration. Int Arch Occup Environ Health 1983;51:365-9.

22 Sato A, Nakajima T, Fujiwara Y, Hirosawa K. Pharmacokinetics of benzene and toluene. Int Arch Occup Environ Health 1983;51:365-9. 